\title{
Elements analysis of Shaanxi's cultural tourism products based on the perspective of the whole industry chain

\author{
Jijiao Jiang ${ }^{1, a}$, Yanchao Kang ${ }^{1, b}$, Chang Liu ${ }^{1, c}$, Yanmei Zhang ${ }^{1, d}$ \\ ajjj_leon@nwpu.edu.cn, ${ }^{b} 15991685854 @ 163 . c o m,{ }^{c} 15991764646 @ 163 . c o m$
} \\ ${ }^{1}$ School of Management, Northwestern Polytechnical University, Xi'an 710129, China.
}

Keywords: Whole industry chain, Shaanxi's cultural tourism, Elements analysis.

\begin{abstract}
Cultural tourism is a higher level of tourism and deeper needs of tourists. To a certain extent, cultural tourism development can reflect the economic level of a region or a country. Tourism-related industries are important factors of cultural tourism development. This paper obtains first-hand data from the Shaanxi's cultural tourism market, and then uses the structural equation model to study the factors of Shaanxi's cultural tourism products and its impact on customer's satisfaction based on the perspective of the whole industry chain. The results show that the factors of the cultural tourism products and the development of the industry chain have a certain influence on the satisfaction of tourists.
\end{abstract}

\section{Introduction}

Cultural tourism has both the characteristics of culture and tourism. In the narrow sense, the cultural tourism is a kind of tourism. In a broad sense, all tourism can be attributed to cultural tourism. Cultural tourism not only has extremely important economic and social benefits, but also has enormously important cultural awareness and heritage function. Cultural consumption has become a fashionable and indispensable part in Chinese daily life ${ }^{[1]}$.From production to consumption, cultural tourism products are interrelated with many industries. But the related research of cultural tourism from the perspective of the whole industry chain is still relatively few. From the theoretical perspective, this paper analyzes the concept of cultural tourism products, and then explores the impact of cultural tourism products on the satisfaction of tourists based on the perspective of the whole industry chain. The research of this paper is of great significance to the development of Shaanxi cultural tourism products and the schematization of cultural tourism.

\section{Literature Review:}

\section{A. Whole industry chain}

The idea of the industrial chain was originally derived from the division of labor inside the enterprise and among different enterprises ${ }^{[2]}$. The formation of benign industry chain is especially important for the industry to obtain and maintain the competitive advantage of the whole industry. The combination of industry chain and value chain is the attention focus of many scholars. The academic community recognized that industrial chain can create value through a series of complex network internal activities ${ }^{[3]}$.Tourism industry chain is long and complex, and the direct composition of the tourism industry involves 7 departments, 35 projects ${ }^{[4]}$.Changfeng Huang ${ }^{[5]}$ uses the input output data of 135 departments of china in 2007as the foundation. He concluded that 9 industries provide direct supply to the tourism industry and 14 industries provide secondary supply to the tourism industry. He also stressed that China's tourism industry chain is not the chain, but the network. BinDai ${ }^{[6]}$ believes that the one hand 14 industries have direct impact on the tourism, and 54 industries have secondary impact on tourism; on the other hand, the tourism industry can affect 20 industries.

\section{B. Cultural Tourism Products}

Cultural tourism is a higher demand of tourists when they travel. Cultural tourism not only allows tourists to experience the local culture, customs, history and culture, but also promotes the culture and customs' heritage and development. S.L.J. Smith ${ }^{[7]}$ is the first one who presents a model 
that describes the product as consisting of five elements: the physical plant, service, hospitality, freedom of choice, and involvement. Physical element is the core of the model and the other four elements are shell. Xiaozhong Yang ${ }^{[8]}$ argues that tourism product is the sum which it is from processing tourism resources to providing tourists consumption of material and spiritual. Kaixia Wang $^{[9]}$ contends that tourism product contains six factors which are food, accommodation, transportation, travel, shopping and entertainment. Hughes emphasizes cultural tourism products should be focused on its sustainability and art. Performing arts and new cultural works may lead to cultural tourism products artistic alienation, misinterpretation. Cultural tourism products not only provides spiritual enjoyment to tourists, but to help tourists feel its culture deeply. The tourists' willing and the attraction of art and culture events are marks which are using to prove tourism actions belong to culture tourism ${ }^{[10]}$.Chaogong Cheng ${ }^{[11]}$ analyses culture tourism products from culture carrier and cultural content and cultural spirit and cultural values qualitatively. L.F.Girard holds that culture tourisms' characteristics consist of aesthetic value, spiritual value, social value, historical value, symbolism and realism. Currently, there is still no united concept approved by almost people to interpret culture tourism products. In this article, culture tourism products are the total of providing cultural entity and service to tourists.

\section{Methodology}

\section{A. Structural equation modeling}

The structural equation model is a statistical method based on the microscopic phenomenon, and its purpose is to establish the structural relationship among the latent variables. The relationship between latent variables is as follows:

$$
\eta=B^{*} \eta+\Gamma^{*} \xi+\zeta \text {. }
$$

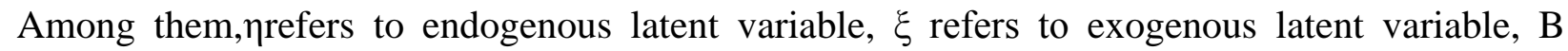
indicates the correlation coefficient between endogenous latent variables, $\Gamma$ refers to the effect of exogenous latent variables on endogenous latent variables. $\zeta$ refers to the residuals of structural equation.

The relationship between the indicators and the latent variables can be expressed in the form of the following form:

$$
\left\{\begin{array}{l}
X=\Lambda_{\mathrm{x}} * \xi+\delta \\
Y=\Lambda_{\mathrm{y}} * \eta+\varepsilon
\end{array}\right.
$$

Among them, $\mathrm{X}$ represents the vector of exogenous indicators, $\Lambda$ xis the correlation coefficient between exogenous latent variables and exogenous indicators, $\delta$ refers to the error term of the exogenous indicators $\mathrm{X}$; $\mathrm{Y}$ represents the vector of endogenous indicators, $\Lambda$ yis the correlation coefficient between endogenous indicators and endogenous latent variables, $\varepsilon$ refers to the error term of the endogenousindicators Y; The method of structural equation model can simultaneously handle multiple dependent variables, and it allows the latent variables to be measured with errors, which is suitable for the study the impact path of the cultural tourism product to customer satisfaction.

\section{B. Model construction}

The cultural characteristics of the whole industry chain of the cultural tourism product should be considered, when we establish the evaluation model of the satisfaction degree of cultural tourism products based on the perspective of the whole industry chain. Through a large number of literature review and induction, this paper constructs the model structure as shown in Figure 1based on the basic elements of tourism products and the perspective of the whole industry chain, 


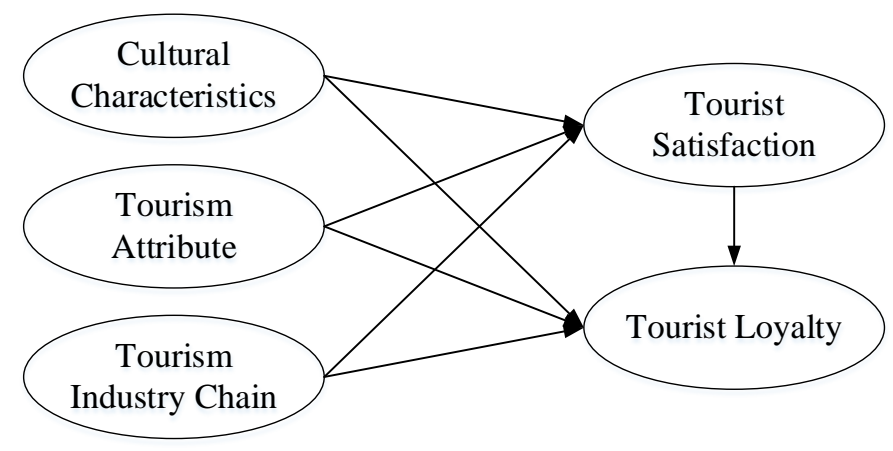

Fig 1 Satisfaction evaluation model of cultural tourism products based on the perspective of the whole industry chain

This paper measures cultural tourism products based on the perspective of the whole industry chain from three dimensions: the cultural characteristics, the tourism attribute and the tourism industry chain condition, and measures tourist satisfaction from two dimensions: tourist satisfaction and tourist loyalty. Among them, cultural characteristics can be from L.F. Girard's cultural tourism aesthetic value, spiritual value, social value, historical value, symbolic significance and real sense of the six dimensions; Tourism attributes can be measured in the six dimensions of tourism that are food, accommodation, traffic, travel, shopping, entertainment. Tourism industry chain can be measured from the whole process of cultural tourism products that tourism resources planning and development, tourism products production, tourism products sales, tourism products consumption. 5 first level indicators and 21secondary indicators and the corresponding question item can be summarized as table 1 :

Table 1 The corresponding relationship between the degree of satisfaction evaluation indicators of cultural tourism based on the perspective of whole industry chain

\begin{tabular}{|c|c|c|}
\hline Latent Variable & Explicit Variable & Questionnaire \\
\hline \multirow{6}{*}{$\begin{array}{c}\text { Cultural } \\
\text { Characteristics }\end{array}$} & Aesthetic Value & $\begin{array}{l}\text { What do you think about the aesthetic value of } \\
\text { the Shaanxi's cultural tourism products }\left(\mathrm{x}_{11}\right)\end{array}$ \\
\hline & Spiritual Value & $\begin{array}{l}\text { What do you think about the spiritual value of } \\
\text { the Shaanxi's cultural tourism products }\left(\mathrm{x}_{12}\right)\end{array}$ \\
\hline & Social Value & $\begin{array}{l}\text { What do you think about the social value of the } \\
\text { Shaanxi's cultural tourism products }\left(\mathrm{x}_{13}\right)\end{array}$ \\
\hline & Historical Value & $\begin{array}{l}\text { What do you think about the historical value of } \\
\text { the Shaanxi's cultural tourism products }\left(\mathrm{x}_{14}\right)\end{array}$ \\
\hline & Symbolic Significance & $\begin{array}{l}\text { What do you think about the symbolic } \\
\text { significance of the Shaanxi's cultural tourism } \\
\text { products }\left(\mathrm{x}_{15}\right)\end{array}$ \\
\hline & Real Sense & $\begin{array}{l}\text { What do you think about the Real Sense of the } \\
\text { Shaanxi's cultural tourism products }\left(\mathrm{x}_{16}\right)\end{array}$ \\
\hline \multirow{6}{*}{ Tourism Attribute } & Food \& Beverage & $\begin{array}{l}\text { What do you think about the food \& beverage } \\
\text { of the Shaanxi's cultural tourism }\left(\mathrm{x}_{21}\right)\end{array}$ \\
\hline & Accommodation & $\begin{array}{l}\text { What do you think about the accommodation of } \\
\text { the Shaanxi's cultural tourism }\left(x_{22}\right)\end{array}$ \\
\hline & Traffic & $\begin{array}{l}\text { What do you think about the traffic of the } \\
\text { Shaanxi's cultural tourism }\left(x_{23}\right)\end{array}$ \\
\hline & Travel & $\begin{array}{l}\text { What do you think about the overall image of } \\
\text { the scenic spots of Shaanxi's cultural tourism } \\
\left(\mathrm{x}_{24}\right)\end{array}$ \\
\hline & Shopping & $\begin{array}{l}\text { What do you think about the shopping services } \\
\text { of the Shaanxi's cultural tourism }\left(\mathrm{x}_{25}\right)\end{array}$ \\
\hline & Entertainment. & $\begin{array}{l}\text { What do you think about the entertainment } \\
\text { services of the Shaanxi's cultural tourism }\left(\mathrm{x}_{26}\right)\end{array}$ \\
\hline Tourism & Economic & What do you think of the economic \\
\hline
\end{tabular}




\begin{tabular}{|c|c|c|}
\hline \multirow[t]{4}{*}{ Industry Chain } & Development & $\begin{array}{l}\text { development of Shaanxi's cultural tourism } \\
\text { industry }\left(\mathrm{x}_{31}\right)\end{array}$ \\
\hline & $\begin{array}{c}\text { Planning\& } \\
\text { development }\end{array}$ & $\begin{array}{l}\text { What do you think about the development of } \\
\text { Shaanxi's cultural tourism resources }\left(\mathrm{x}_{32}\right)\end{array}$ \\
\hline & Products Production & $\begin{array}{l}\text { What do you think about the abundance of } \\
\text { Shaanxi's cultural tourism products }\left(x_{33}\right)\end{array}$ \\
\hline & Products Consumption & $\begin{array}{l}\text { What do you think of the consumer market of } \\
\text { Shaanxi's cultural tourism products }\left(\mathrm{x}_{34}\right)\end{array}$ \\
\hline \multirow{3}{*}{ Tourist Satisfaction } & $\begin{array}{l}\text { The Satisfaction } \\
\text { Relative to Demand }\end{array}$ & $\begin{array}{l}\text { Compared with needs, your satisfaction with } \\
\text { the Shaanxi cultural tourism products }\left(\mathrm{y}_{11}\right)\end{array}$ \\
\hline & $\begin{array}{l}\text { The Satisfaction } \\
\text { Relative to } \\
\text { Expectations }\end{array}$ & $\begin{array}{l}\text { Compared with expectations, your satisfaction } \\
\text { with the Shaanxi cultural tourism products } \\
\left(\mathrm{y}_{12}\right)\end{array}$ \\
\hline & Overall satisfaction & $\begin{array}{l}\text { your overall satisfaction with the Shaanxi } \\
\text { cultural tourism products }\left(\mathrm{y}_{13}\right)\end{array}$ \\
\hline \multirow[b]{2}{*}{ Tourist loyalty } & Probability of Revisit & Are you willing to revisit $\left(\mathrm{y}_{21}\right)$ \\
\hline & Recommend to friends & $\begin{array}{l}\text { Are you willing to recommend this place to } \\
\text { your friends }\left(y_{22}\right)\end{array}$ \\
\hline
\end{tabular}

\section{Results:}

\section{A. Data Source}

We face to face interview the visitors in scenic spots of Shaanxi's cultural tourism. Our team interview296 visitors, and get 276 complete questionnaires. After 83 obvious regular or contradictory questionnaires were excluded, remaining 193 questionnaire, and the effective rate is $69.9 \%$. Descriptive statistical analysis of the measurement terms of questionnaires is as shown in Table 2:

Table 2 Descriptive statistics of measurement terms

\begin{tabular}{c|c|c|c|c|c|c|c|c|c}
\hline Indicators & Mean & $\begin{array}{c}\text { Standard } \\
\text { deviation }\end{array}$ & $\begin{array}{c}\text { Skewnes } \\
\mathrm{s}\end{array}$ & Kurtosis & Indicators & Mean & $\begin{array}{c}\text { Standard } \\
\text { deviatio } \\
\mathrm{n}\end{array}$ & $\begin{array}{c}\text { Skewnes } \\
\mathrm{s}\end{array}$ & Kurtosis \\
\hline $\mathrm{x}_{11}$ & 3.95 & 0.54 & -0.03 & 0.43 & $\mathrm{x}_{26}$ & 4.01 & 0.57 & -0.26 & 1.14 \\
\hline $\mathrm{x}_{12}$ & 4.02 & 0.73 & -0.15 & -0.76 & $\mathrm{x}_{31}$ & 3.85 & 0.60 & -0.15 & 0.20 \\
\hline $\mathrm{x}_{13}$ & 3.93 & 0.65 & 0.07 & -0.64 & $\mathrm{x}_{32}$ & 3.68 & 0.72 & -0.07 & -0.23 \\
\hline $\mathrm{x}_{14}$ & 4.34 & 0.65 & -0.47 & -0.67 & $\mathrm{x}_{33}$ & 4.22 & 0.68 & -0.61 & 0.56 \\
\hline $\mathrm{x}_{15}$ & 4.07 & 0.64 & -0.24 & 0.12 & $\mathrm{x}_{34}$ & 3.84 & 0.68 & -0.23 & 0.05 \\
\hline $\mathrm{x}_{16}$ & 3.98 & 0.66 & -0.15 & -0.20 & $\mathrm{y}_{11}$ & 3.95 & 0.52 & -0.07 & 0.72 \\
\hline $\mathrm{x}_{21}$ & 3.73 & 0.60 & -0.29 & 0.22 & $\mathrm{y}_{12}$ & 3.68 & 0.78 & 0.03 & -0.52 \\
\hline $\mathrm{x}_{22}$ & 3.59 & 0.68 & 0.11 & -0.26 & $\mathrm{y}_{13}$ & 3.83 & 0.59 & 0.06 & -0.28 \\
\hline $\mathrm{x}_{23}$ & 3.74 & 0.72 & -0.32 & 0.06 & $\mathrm{y}_{21}$ & 3.98 & 0.57 & -0.25 & 0.98 \\
\hline $\mathrm{x}_{24}$ & 3.94 & 0.59 & 0.01 & -0.04 & $\mathrm{y}_{22}$ & 4.13 & 0.67 & -0.32 & -0.12 \\
\hline $\mathrm{x}_{25}$ & 3.80 & 0.76 & 0.03 & -0.63 & & & & & \\
\hline
\end{tabular}

\section{B. reliability test}

Reliability reflects the validity of the questionnaires data. we use the SPSS21.0 to calculate the various latent variable Cronbach's $\alpha$ coefficients. When $\alpha>0.5$ means that the data is reliable; when $\alpha>0.7$ means the data is higher reliable. As Table 3 shows, The Cronbach's $\alpha$ coefficients of all the latent variables were above 0.6 , which represent that the data reliability is high and the internal consistency among the latent variables is hunk. The results show that the KMO value of the variables is 0.855 , which indicates that the variables are suitable for the factor analysis. 
Table 3 Reliability test of questionnaire data

\begin{tabular}{c|c|c|c|c|c}
\hline & $\begin{array}{c}\text { Cultural } \\
\text { Characteristics }\end{array}$ & $\begin{array}{c}\text { Tourism } \\
\text { Attribute }\end{array}$ & $\begin{array}{c}\text { Tourism } \\
\text { Industry Chain }\end{array}$ & $\begin{array}{c}\text { Tourist } \\
\text { Satisfaction }\end{array}$ & $\begin{array}{c}\text { Tourist } \\
\text { loyalty }\end{array}$ \\
\hline Cronbach's $\alpha$ & 0.688 & 0.627 & 0.613 & $0.486(0.616)$ & 0.602 \\
\hline
\end{tabular}

C. Evaluation model analysis:

After constructing the evaluation model of cultural tourism satisfaction, the paper uses the Amos software to calculate the path coefficient of each latent variable, and then get standardized path coefficients as shown in Fig 2:

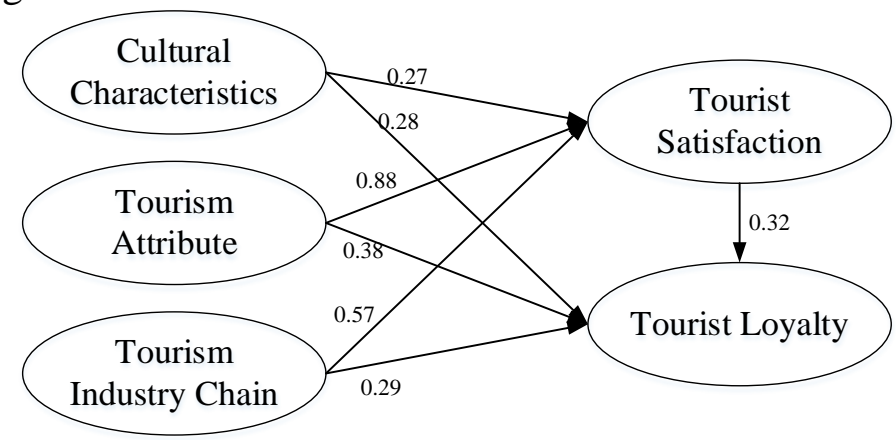

Fig 2 Model path coefficient fitting

In the service industry, customer loyalty is the ultimate pursuit of customer satisfaction. Largely, customers will buy again or recommend to others because of customers loyalties. So is culture tourism. Tourist satisfaction and tourist loyalty are influenced by cultural characteristics of cultural tourism products and tourism property and industry chain development situation positively shown in Table 4.Cultural characteristics of cultural tourism products affect tourists' path coefficient 0.27 compared with tourism property's 0.88 . It indicates that the current cultural characteristics of Shaanxi cultural tourism product have big potential to develop, in accordance with development of cultural tourism in Shaanxi Province currently. And development of tourism-related industry chain also has a positive impact on tourist satisfaction and tourist loyalty in the perspective of the whole industry chain. It advisably proves the hypothesis in this paper. Indirect relationship between tourist satisfaction and loyalty of visitors of cultural tourism products is not very strong and the result shows that before coming destination tourists are curious of culture of destination, but when they have been acquired of it, their strong willing they come again become die away. However, good reputation coming from increasing tourist satisfaction is good to culture tourism largely.

\section{Discussion \& Conclusion:}

The whole industry chain Perspective cultural tourism products have three elements: cultural identity, property and tourism development of the tourism industry chain. This paper constructs a structural equation model based on tourists satisfaction influenced by the culture tourism and independent variable covers cultural identity, tourism property and tourism development for the tourism industry chain and outcome variable covers tourist satisfaction and tourist loyalty. What's more, this paper uses the first data through field study to analyze and draw the related conclusion like following.

(1)The path coefficient of cultural characteristics of cultural tourism products influencing on customer satisfaction is 0.27 and the path coefficient of cultural characteristics directly influencing on tourist loyalty is 0.28 , the indirect path coefficient is 0.086 , the total effect is 0.366 . This research shows that cultural characteristics of culture tourism products impact tourist satisfaction and tourist loyalty obviously.

(2)Tourism properties of cultural tourism products have a direct impact on tourist satisfaction reaching to 0.88 and that indicates the six tourism elements are aims to which tourist pay attention. Tourism properties having a direct impact on tourist loyalty is 0.38 and indirect impact is 0.282 , so total influence is 0.662 .This result reveals that the tourism property can bring high tourist loyalty.

(3)Development of the tourism industry chain directly affecting customer satisfaction path coefficient is 0.57 , which indicates that development of the industrial chain has direct and 
significant impact on tourist satisfaction. Development of the tourism industry chain having a direct impact on tourist loyalty is 0.29 and indirect impact is 0.182 , so total influence is 0.472 .This result reveals that the Development of the tourism industry chain has some impact on tourist satisfaction and tourist loyalty.

So we make the following suggestions on the development of cultural tourism products.

(1) In product development: because the cultural characteristics of the cultural tourism products have a certain impact on customer satisfaction and loyalty, We should pay attention to highlight and publicize the cultural characteristics of cultural tourism scenic spots, so as to increase the cultural attraction of the cultural tourism products and expand the tourist market of cultural tourism;

(2) In Product operations: the occurrence of cultural tourism has a strong dependence on the basic attributes of the tourism that are food, accommodation, traffic, travel, shopping, and entertainment. A favorable tourism experience will bring better customer satisfaction from tourists, also may bring potential revisit and recommendation. Turning tourism experience into marketing propaganda is what tourism needs to learn from;

(3)In terms of product support: cultural tourism involves a long industrial chain from planning to production and then to consumption. Quality tourism industry chain is not only an important support for the development and operation of cultural tourism products, but also an important guarantee for the sustainable competitiveness of cultural tourism products.

\section{Acknowledgements}

This paper was supported by grant number NO.2015KRM028 from the soft science research project of Shaanxi province. The title of project is the research of Shaanxi cultural tourism products system construction based on the whole industry chain perspective. Communication Mailbox: jjj_leon@nwpu.edu.cn.

\section{References}

[1] Cong S, Li Y. The Study about Development Status, Trends and Paths of Cultural Industry in China[J]. Energy Procedia, 2011, 5(1):2078-2081.

[2] Guifu Liu. Research on The Basic Theories of Industry Chain[D].Changchun, Jilin science and Technology Press,2006:25-27.

[3] Changli Feng, Ying Lan, Jian Zhou. A Case Study on the Value Creation Path of COCFCO's Whole Industry Chain Strategy [J]. Management case study and comment, 2012, 02: 135-145.

[4] Xiaoyun Zhao. Research on the Specificity of Tourism Industry and the Form of Tourism Industry Chain [J]. Shanghai economic research, 2010,06: 42-47.

[5] Changfeng Huang, Hui Sun, Lunzhi He. Study on the Identification of China's Tourism Industry Chain. Tourism Tribune [J], 2011, 01 (1): 18-24.

[6] Bin Dai, Juping Shu. Tourism Industry Association: the framework and an Empirical Study of Beijing [J]. Journal of Beijing International Studies University, 2005, 05: 7-15.

[7] S.L.J. Smith. The tourism product. Annals of Tourism Research, 1994, 21 (3): 582-595.

[8] Xiaozhong Yang, LinLu, Guangsheng Zhang. Relationship between Resort Life Cycle and Evolution of Tourism Product Structure)Taking Putuoshan Mountain as an Example [J].Geographic Sciences, 2004, 04 (4): 500-505.

[9] Wang Kaixia. Components of tourism products and the development of tourism in Shanxi [J].Economist, 2006, 10: 265-266.

[10] Howard L. Hughes. Theatre in London and the interrelationship with tourism[J].Tourism Management, 1998, 19 (5) :445-452. 
[11] Chaogong Cheng. Study of the evolution System of Cultural Tourism Product[M]. Jiangnan University, 2009:6-9. 